\title{
OPEN Incisional hernia after surgical correction of abdominal congenital anomalies in infants: a systematic review with meta-analysis
}

\author{
Laurens D. Eeftinck Schattenkerk $\mathbb{1}^{1,2} \llbracket$, Gijsbert D. Musters ${ }^{1}$, David J. Nijssen ${ }^{1}$, \\ Wouter J. de Jonge ${ }^{2,3}$, Ralph de Vries ${ }^{4}$, L. W. Ernest van Heurn ${ }^{1,2}$ \& Joep PM. Derikx ${ }^{1,2}$
}

Incisional hernia $(\mathrm{IH})$ in children could result in life-threatening complications, including incarceration and bowel strangulation. The incidence and risk factors of $\mathrm{IH}$ in infants are scarcely reported. Since $\mathrm{IH}$-correction may require extensive surgery and a long recovery program, identifying infants and birth defects at risk, may lead to a different approach during the primary surgery. Therefore, the aim of this review is to systematically review the available data on the incidence of $\mathrm{IH}$ following surgery for congenital anomalies in infants. All studies describing $\mathrm{IH}$ were considered eligible. PubMed and Embase were searched and risk of bias was assessed. Primary outcome was the incidence of $\mathrm{IH}$, secondary outcomes were difference in IH occurrence between disease severity (complex vs simple) and closure method (SILO vs primary closure) in gastroschisis patients. A meta-analysis was performed to pool the reported incidences in total and per congenital anomaly separately. Subgroup analysis within gastroschisis articles was performed. The 50 included studies represent 3140 patients. The pooled proportion of $\mathrm{IH}$ was $0.03\left(95 \% \mathrm{Cl} 0.02-0.05 ; I^{2}=79 \%, p \leq 0.01\right)$ all anomalies combined. Gastroschisis (GS) reported highest pooled proportion $0.10\left(95 \% \mathrm{Cl} 0.06-0.17 ; n=142 / 1273 ;\left.\right|^{2}=86 \%\right.$; $p \leq 0.01)$. SILO closure (OR 3.09) and simple gastroschisis, i.e. without additional anomalies, (OR 0.18) were of significant influence. This review reports the incidence of $\mathrm{IH}$ in infants with different congenital abdominal anomalies, of which gastroschisis reported the highest risk. In GS patients, complex GS and SILO closure are risk factors for IH development.

Incisional hernia $(\mathrm{IH})$ is a dreaded complication after abdominal surgery in children. It may result in serious lifethreatening complications, including incarceration and bowel strangulation ${ }^{1,2}$. In addition, it is is a burden on the quality of life and may affect the development of the child ${ }^{3,4}$. The incidence and risk factors of IH in neonates are scarcely reported and therefore surgeons often refer to studies done in the adult population. For obvious reasons though, taking measures to prevent smoking and obesity in the infantile cohort would not aid in lowering IH rate $^{5}$. The studies that do report IH in the paediatric population reported an incidence between 0.7 and $3.2 \%^{6-9}$. During the last decades major advancements have been made in the postnatal care of neonates with congenital anomalies. Those developments, such as extracorporeal membrane oxygenation (ECMO) and total parenteral nutrition, have increased survival of this crucial period ${ }^{10}$. Because more neonates survive, there has been an increase in abdominal paediatric surgery procedures ${ }^{10,11}$. As the total numbers of abdominal procedures rises, an increase in total accounts of $\mathrm{IH}$ is also to be expected.

IH correction may require extensive surgery and a long recovery program. Identifying infants and birth defects at risk, may lead to a different approach during the primary surgery. Therefore, the aim of this review is to estimate the incidence of incisional hernia following surgery for congenital anomalies in infants (less than 2 years of age) with a systematic review.

\footnotetext{
${ }^{1}$ Department of Paediatric Surgery, Emma Children's Hospital, Amsterdam University Medical Centre, University of Amsterdam and Vrije Universiteit Amsterdam, Meibergdreef 9, 1005 AZ Amsterdam, The Netherlands. ${ }^{2}$ Tytgat Institute for Liver and Intestinal Research, Amsterdam University Medical Centre, University of Amsterdam, Amsterdam, The Netherlands. ${ }^{3}$ Department of General, Visceral-, Thoracic and Vascular Surgery, University Hospital Bonn, Bonn, Germany. ${ }^{4}$ Medical Library, Vrije Universiteit, Amsterdam, The Netherlands. ${ }^{\square}$ email: I.d.eeftinkckschattenkerk@amsterdamumc.nl
} 


\section{Methods}

Studies were selected according to the criteria outlined below based on the PRISMA Guidelines ${ }^{12}$. Our protocol has been registered with the International Prospective Register of Systematic Reviews (PROSPERO) on 7 March 2019 (registration number: CRD42019119268).

Participants. All studies reporting on IH after surgical correction of abdominal congenital anomalies in infants were considered for this review. Studies reporting on other complications, animal studies, in vitro studies, non-English, conference abstracts and studies with less than ten cases were excluded.

Search strategy. The electronic databases of the National Institutes of Health PubMed and EMBASE were systematically searched in February 2020 using both simple search terms as well as hierarchical family forms (e.g. MESH). The clinical data expert (RV) aided in the formation of the search strategy. The search combined four groups of search terms and their equivalents: (1) terms related to the age at the moment of surgery (e.g. neonate); (2) terms related to the location of surgery (e.g. abdominal surgery); (3) terms related to congenital abdominal defects (e.g. omphalocele); (4) terms related to incisional hernia (e.g. cicatricial hernia). Mesh and search terms used in PubMed are included in Appendix 1.

Primary and secondary outcomes. The primary endpoint was the pooled percentage of IH. Secondary endpoint included the pooled percentage per congenital anomaly and identification of possible risk factors such as surgical procedure and disease severity by means .

A Forest plot, containing the estimated overall pooled proportion of $\mathrm{IH}$ and the corresponding 95\% CI was created using Graphpad Prism version 8. In the Forest plot we also reported the pooled proportion and CI per anomaly if; (1) IH was reported in at least three studies for the anomaly OR (2) if the total number of patients all studies on an anomaly combined was $\geq 100$ patients; (3) there was at least one event of IH present all studies on a specific anomaly combined. If these criteria were not met the anomaly was reported under the forest plot as residual. These residuals were still included in the analysis for overall pooled proportions.

For all studies with multiple arms, data of both trial-arms were combined or, if only one arm matched the inclusion criteria, the appropriate arm was used. Additional extracted parameters were: author, country of conduct, year of publication, journal, study design, duration of follow-up, duration of study, number of participants, type of congenital anomaly, subdivision within anomaly, time to IH, repeat surgery because of IH, history of stoma data was extracted on. Duration of follow up was described as median with range, mean with/without standard deviation or citated text following each article's own description. Duration was either reported in month or years recalculated from the reported value if necessary.

For studies describing gastroschisis, type of closure (by SILO or primary) and severity of disease (complex or simple) was noted following definitions used by the author. Studies deemed gastroschisis complex when a patient had additional anomalies, such as intestinal atresia. If the patient only suffered from a gastroschisis, it was accepted as simple gastroschisis.

Data extraction. Titles and abstracts were screened by two independent authors (LES, DN) using Rayyan. Rayyan is an online based software that facilitates blind collaboration among reviewers. Disagreements were resolved by discussion between the two review authors. A third specialist author (JD or GM) was consulted if consensus was not reached. Afterwards the full text of the remaining articles was read to determine eligibility for inclusion (LES, DN). If the full text was not found the authors were contacted. Of the included articles the reference list was cross-checked to find any additional articles.

Validity and eligibility assessment. All included articles were assessed for the methodological quality and risk of bias using the Newcastle Ottawa quality assessment scale ${ }^{13}$. LES and DN did the assessment separately.

Data synthesis. For each study, a weighted average of the logit proportions of IH was determined by the use of the generic inverse variance method. The logit proportions were back transformed to the summary estimate and $95 \%$ CIs were obtained in a summary proportion representing the pooled proportion of the IH. Heterogeneity was assessed using the $\mathrm{I}^{2}$ and $\chi^{2}$ statistics. Analysis was performed using R-studio version 3.6.1 (package "meta" (Schwarzer, 2007) and "metaprop" (Viachtbauer, 2010)). The random-effects model was used for interpretation. Heterogeneity was deemed significant if the pooled data's $p$ value was $<0.05$ or $\chi^{2}$ statistics were $\geq 75$. Heterogeneity was interpreted as small $\left(\mathrm{I}^{2} \leq 0.25\right)$, medium $\left(\mathrm{I}^{2}=0.25-0.50\right)$ or strong $\left(\mathrm{I}^{2} \geq 0.50\right)$, according to Higgins $^{14}$. The gastroschisis subgroup analysis were performed using review manager (version 5.3) to generate forest plots. In this part of the meta-analysis the odds ratio was calculated using Mantel-Haenszel statistics, using the random-effects model to interpret results.

\section{Results}

Study characteristics. During the search 5794 records were identified. Automated removal of duplicates left 3909 records for title and abstract screening. Of these 3909 records, 722 met the criteria for full text assessment. One article was included after screening references of included articles. Full text evaluation resulted in 50 studies, which were included for quantitative analysis (Fig. 1). These 50 studies represent 3140 patients (Table 1). Risk of bias was assessed and is shown in Table 2, most of the included studies reported fair quality on the NOS. 


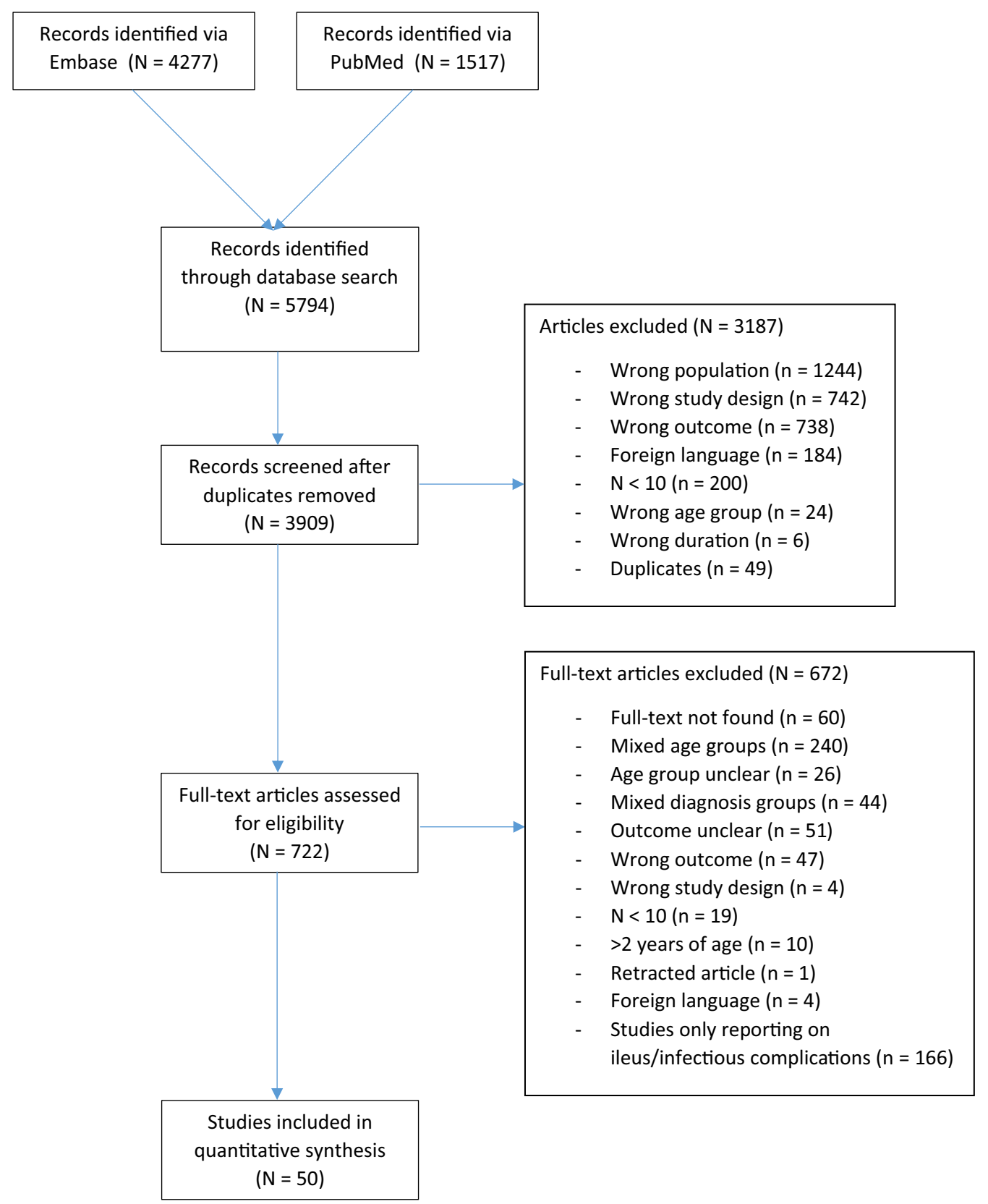

Figure 1. Flow diagram article selection.

Six were prospective cohort studies, one combined a prospective-with a retrospective cohort, four were multicentre retrospective cohort studies, thirty-eight were retrospective cohort studies and one was a matched case-control study. None of the studies had a randomized design. Nineteen of the studies were conducted in North America, sixteen in Europe, eleven in Asia, three in Africa and one in the Middle-East. Follow up was at least half a year in $24(48 \%)$ of all studies.

Overall proportions. In 3140 patients 188 incisional hernias occurred ${ }^{15-64}$. None of the studies reported on the mode of diagnosis or the size of the defect. The pooled proportion of IH (Fig. 2) with all anomalies combined was 0.03 (95\% CI $\left.0.02-0.05 ; \mathrm{I}^{2}=79 \%, p \leq 0.01\right)$. Separate pooled proportions were calculated for the following birth defects: Gastroschisis 0.10 (95\% CI $0.06-0.17 ; \mathrm{n}=142 / 1273 ; \mathrm{I}^{2}=86 \% ; p \leq 0.01$ ); Anorectal malformations 0.01 (95\% CI 0.00-0.05; $\left.\mathrm{n}=4 / 426 ; \mathrm{I}^{2}=29 \% ; p=0.96\right)$; Duodenal obstruction 0.01 (95\% CI 0.00-0.03; $\mathrm{n}=3 / 308$; $\left.\mathrm{I}^{2}=0 \% ; p=0.77\right)$; Biliary atresia 0.03 (95\% CI $\left.0.02-0.06 ; \mathrm{n}=8 / 259 ; \mathrm{I}^{2}=0 \% ; p=0.91\right)$; Hirschsprung's disease 0.03 (95\% CI 0.01-0.06; $\mathrm{n}=7 / 238 ; \mathrm{I}^{2}=0 \% ; p=0.93$ ); Congenital diaphragmatic hernia 0.03 (95\% CI 0.01-0.10; $\left.\mathrm{n}=7 / 201 ; \mathrm{I}^{2}=34 \% ; p=0.91\right)$; Small intestinal atresia 0.03 (95\% CI $0.02-0.07 ; \mathrm{n}=7 / 201 ; \mathrm{I}^{2}=0 \%$; $\left.p=0.91\right)$; Omphalocele 0.07 (95\% CI 0.03-0.17; $\left.\mathrm{n}=10 / 131 ; \mathrm{I}^{2}=42 \% ; p=0.32\right)$. Choledochal cyst $(\mathrm{N}=57)$ and Meckel $(\mathrm{N}=46)$ are included in the overall proportion but were not reported separately as they did not meet the described criteria. 


\begin{tabular}{|c|c|c|c|c|c|c|c|c|c|}
\hline Study (name, year) & Study design & Anomaly & $I H / n$ & Follow-up & Time to hernia & Redo & Stoma & Type of surgery & $\begin{array}{l}\text { Location of incision } \\
\text { (n) }\end{array}$ \\
\hline Dariel, 2015 & Retrospective & Gastroschisis & $6 / 41$ & $3.1 y(1-9)$ & $165-1962 d$ & $5 / 6$ & No & NA & NA \\
\hline Chiu, 2006 & Retrospective & Gastroschisis & $6 / 43$ & NR & NR & NR & No & NA & NA \\
\hline Henrich, $2007^{* 1}$ & Prospective & Gastroschisis & $3 / 22$ & $6.3 y(1-10)$ & NR & $0 / 3$ & No & NA & NA \\
\hline Payne, 2010 & Case-control & Gastroschisis & $2 / 127$ & $3.3 y(2.2)$ & $\mathrm{NR}$ & NR & No & NA & NA \\
\hline Orion, 2011 & Retrospective & Gastroschisis & $14 / 44$ & $11.4 \mathrm{~m}$ & "Prior to discharge" & $4 / 14$ & No & NA & NA \\
\hline Weil, 2011 & Retrospective & Gastroschisis & $43 / 190$ & NR & NR & NR & No & NA & NA \\
\hline Friedmacher, 2014 & Retrospective & Gastroschisis & $3 / 108$ & $15 y(4-37)$ & NR & $3 / 3$ & No & NA & NA \\
\hline Tullie, 2016 & Retrospective & Gastroschisis & $10 / 39$ & $53 \mathrm{~m}(10-101)$ & NR & NR & No & NA & NA \\
\hline Dingemann, 2017 & Multi-centre & Gastroschisis & $2 / 39$ & "At least 1y" & 4 months & $2 / 2$ & No & NA & NA \\
\hline Zmora, 2016 & Retrospective & Gastroschisis & $1 / 11$ & $16 \mathrm{~m}$ & NR & NR & No & NA & NA \\
\hline Mutanen, $2018^{* 1}$ & Multi-centre & Gastroschisis & $3 / 34$ & Unclear & NR & $3 / 3$ & No & NA & NA \\
\hline Hawkins, 2019 & Multi-centre & Gastroschisis & $49 / 566$ & NR & NR & NR & No & NA & NA \\
\hline Demirogullari, 2011 & Retrospective & ARM & $2 / 157$ & NR & NR & $0 / 2$ & Yes & Laparoscopy & NA \\
\hline de Vos, 2011 & Retrospective & ARM & $2 / 39$ & $5.5 \mathrm{y}$ & NR & NR & Yes & Both & NA \\
\hline Yang, 2014 & Retrospective & ARM & $0 / 20$ & $1 y$ & NA & NA & Yes & Laparotomy & Sub-umbilical (20) \\
\hline Almosallam, 2016 & Retrospective & ARM & $0 / 104$ & NR & NA & NA & Yes & Laparotomy & NR \\
\hline Diao, 2016 & Retrospective & ARM & $0 / 16$ & $16 \mathrm{~m}(8-26)$ & NA & NA & No & Laparoscopy & NA \\
\hline Ren, 2018 & Retrospective & ARM & $0 / 25$ & $18 \mathrm{~m}$ & NA & NA & Yes & Laparoscopy & NA \\
\hline Ren, 2019 & Retrospective & ARM & $0 / 48$ & $59.4 \mathrm{~m} \mathrm{(13.7)}$ & NA & NA & Yes & Laparoscopy & NA \\
\hline Xiao, 2018 & Retrospective & ARM & $0 / 17$ & $2.6 y(2-4)$ & NA & NA & No & Laparoscopy & NA \\
\hline Escobar, 2004 & Retrospective & Duodenal obstruction & $1 / 169$ & "Over 30ys" & 10 months & $1 / 1$ & No & Laparotomy & NR \\
\hline Takahashi, 2010 & Prospective & Duodenal obstruction & $0 / 18$ & "Few months" & NA & NA & No & Laparotomy & $\begin{array}{l}\text { Sub-umbilical (8) } \\
\text { Transverse (10) }\end{array}$ \\
\hline Kozlov, 2010 & Retrospective & Duodenal obstruction & $0 / 27$ & Unclear & NA & NA & No & Laparoscopy & NA \\
\hline Ghaffarpour, 2013 & Retrospective & Duodenal obstruction & $0 / 28$ & "At least $1 \mathrm{~m}$ " & NA & NA & No & Laparotomy & Supra-umbilical \\
\hline Jensen, 2013 & Retrospective & Duodenal obstruction & $2 / 66$ & NR & NR & NR & No & Both & Transverse (44) \\
\hline Madadi-Sanjani, 2015 & Retrospective & Biliary atresia & $5 / 153$ & $7.8 \mathrm{~m}(4.8-17.1)$ & NR & NR & No & Laparotomy & Transverse (153) \\
\hline Bing, 2019 & Prospective & Biliary atresia & $1 / 25$ & $25.4 \mathrm{~m}(6-59)$ & 2 days & $1 / 1$ & No & Laparoscopy & NA \\
\hline Ramos-Gonzalez, 2019 & Retrospective & Biliary atresia & $2 / 81$ & $5.7 y(1-11.6)$ & NR & $2 / 2$ & No & Laparotomy & Transverse (81) \\
\hline Escobar, 2005 & Retrospective & Hirschsprung & $2 / 33$ & $11 y(9)$ & NR & $2 / 2$ & No & Laparotomy & NR \\
\hline Bianchi, 1998 & Retrospective & Hirschsprung & $1 / 13$ & "Range 7 m-13y" & NR & NR & No & Laparotomy & Oblique (13) \\
\hline Teitelbaum, 1998 & Retrospective & Hirschsprung & $1 / 24$ & $2.8 \mathrm{y}(1.7)$ & NR & $1 / 1$ & No & Laparotomy & Oblique (24) \\
\hline Santos, 1999 & Retrospective & Hirschsprung & $1 / 65$ & NR & NR & NR & NR & Laparotomy & NR \\
\hline Sauer, 2005 & Retrospective & Hirschsprung & $1 / 24$ & $7.3 \mathrm{~m} \mathrm{(9.7)}$ & NR & $1 / 1$ & No & Laparotomy & Umbilical (24) \\
\hline Gao, $2019^{* 1}$ & Retrospective & Hirschsprung & $1 / 35$ & NR & NR & $1 / 1$ & NR & Laparotomy & NR \\
\hline Jona, 2001 & Retrospective & Hirschsprung & $0 / 44$ & NR & NA & NA & No & Laparoscopy & NA \\
\hline Ibrahim, 2012 & Prospective & Diaphragmatic hernia & $0 / 15$ & $20 \mathrm{~m}$ & NA & NR & No & Laparoscopy & NA \\
\hline Tyson, 2017 & Retrospective & Diaphragmatic hernia & $4 / 54$ & $27 \mathrm{~m}(0.9-89)$ & NR & NR & No & Both & NR \\
\hline de Bie, 2019 & Multi-centre & Diaphragmatic hernia & $0 / 62$ & "At least 1y" & NA & NR & No & Laparotomy & Sub-costal (62) \\
\hline Dewberry, 2019 & Retrospective & Diaphragmatic hernia & $3 / 70$ & Unclear & NR & NR & No & NR & NR \\
\hline Stollman, 2008 & Retrospective & Small intestinal atresia & $4 / 110$ & Unclear & NR & NR & No & Laparotomy & NR \\
\hline Festen, 2002 & Multi-centre & Small intestinal atresia & $1 / 15$ & $24 \mathrm{~m} \mathrm{(2-96)}$ & 9 months & NR & No & Laparoscopy & NA \\
\hline Banieghbal, 2007 & Prospective & Small intestinal atresia & $0 / 16$ & $6 \mathrm{~m}$ & NA & NA & No & Laparoscopy & NA \\
\hline $\mathrm{Li}, 2012$ & Retrospective & Small intestinal atresia & $0 / 35$ & "Range 2-27 m" & NA & NA & No & Laparoscopy & NA \\
\hline Mutanen, $2018^{* 1}$ & Multi-centre & Small intestinal atresia & $2 / 25$ & Unclear & NR & $2 / 2$ & NR & Laparotomy & NR \\
\hline Saxena, 2011 & Prospective & Omphalocele & $1 / 50$ & "3 years" & NR & $1 / 1$ & No & NA & NA \\
\hline Lee, 2006 & Retrospective & Omphalocele & $1 / 20$ & "Over 22ys" & NR & $1 / 1$ & No & NA & NA \\
\hline Henrich, $2007^{* 1}$ & Prospective & Omphalocele & $3 / 15$ & $6.3 y(1-10)$ & NR & NR & No & NA & NA \\
\hline Jiang, 2016 & Retrospective & Omphalocele & $4 / 24$ & NR & NR & NR & No & NA & NA \\
\hline Zmora, 2016 & Retrospective & Omphalocele & $1 / 6$ & $16 \mathrm{~m}$ & NR & NR & No & NA & NA \\
\hline Michel, 2018 & Retrospective & Omphalocele & $0 / 16$ & $11 \mathrm{~m}(1-48)$ & NA & NR & No & NA & NA \\
\hline Diao, 2014 & Retrospective & Choledochal cyst & $0 / 27$ & $24 \mathrm{~m}(1-50)$ & NA & NA & No & Laparoscopy & NA \\
\hline van den Eijnden, 2017 & Retrospective & Choledochal cyst & $0 / 30$ & $13.6 y(0.8-26)$ & NA & NA & No & Both & NR \\
\hline Önen, 2003 & Combined & Meckel's diverticula & $0 / 34$ & NR & NA & NA & No & Laparotomy & NR \\
\hline Gao, $2019^{* 1}$ & Retrospective & Meckel's diverticula & $0 / 12$ & NR & NA & NA & No & Laparotomy & NR \\
\hline
\end{tabular}

Table 1. Study characteristics. ${ }^{* 1}$ Henrich 2007, Mutanen 2018 and Gao 2019 each described 2 separate anomalies. $N A$ not applicable, $N R$ not reported. 


\begin{tabular}{|c|c|c|c|c|c|}
\hline \multirow[b]{2}{*}{ Author } & \multirow[b]{2}{*}{ Year } & \multicolumn{4}{|c|}{ New Ottawa Scale (NOS) } \\
\hline & & $\begin{array}{l}\text { Selection } \\
\text { (0-4 asterisks) }\end{array}$ & \begin{tabular}{|l} 
Comparability \\
(0-2 asterisks)
\end{tabular} & $\begin{array}{l}\text { Outcome } \\
\text { (0-3 asterisks) }\end{array}$ & \begin{tabular}{|l} 
Total \\
$(0-9)$
\end{tabular} \\
\hline Stollman & 2008 & *** & * & $* * *$ & 7 \\
\hline Ibrahim & 2012 & *** & - & $* *$ & 5 \\
\hline Festen & 2002 & ** & ** & $* *$ & 6 \\
\hline Escobar & 2005 & *** & - & $* * *$ & 6 \\
\hline Dariel & 2015 & $* * *$ & * & $* * *$ & 7 \\
\hline Demirogullari & 2011 & ** & - & $* *$ & 4 \\
\hline Bianchi & 1998 & $* * *$ & - & $* * *$ & 6 \\
\hline Teitelbaum & 1998 & ** & - & $* * *$ & 5 \\
\hline Santos & 1999 & *** & - & $* * *$ & 6 \\
\hline \begin{tabular}{|l|} 
Saxena \\
\end{tabular} & 2001 & $* * *$ & * & $* * *$ & 7 \\
\hline Önen & 2003 & $* * *$ & - & $* *$ & 5 \\
\hline Escobar & 2004 & *** & * & ** & 6 \\
\hline Sauer & 2005 & ** & ** & ** & 6 \\
\hline \begin{tabular}{|l|} 
Chiu \\
\end{tabular} & 2006 & *** & * & ** & 6 \\
\hline \begin{tabular}{|l|} 
Lee \\
\end{tabular} & 2006 & ** & * & $* * *$ & 6 \\
\hline Banieghbal & 2007 & ** & - & $* * *$ & 5 \\
\hline Henrich & 2007 & *** & - & * & 4 \\
\hline Payne & 2010 & **** & * & $* * *$ & 8 \\
\hline \begin{tabular}{|l} 
Takahashi \\
\end{tabular} & 2010 & $* * *$ & * & ** & 6 \\
\hline de Vos & 2011 & $* * *$ & - & $* * *$ & 6 \\
\hline \begin{tabular}{|l|} 
Kozlov \\
\end{tabular} & 2010 & $* * *$ & ** & $* *$ & 7 \\
\hline Orion & 2011 & *** & - & $* *$ & 5 \\
\hline $\mathrm{Li}$ & 2012 & *** & - & ** & 5 \\
\hline Weil & 2011 & $* * *$ & * & $* * *$ & 7 \\
\hline \begin{tabular}{|l} 
Ghaffarpour \\
\end{tabular} & 2013 & $* * *$ & * & $* *$ & 6 \\
\hline Jensen & 2013 & $* * *$ & ** & $* *$ & 7 \\
\hline Diao & 2014 & ** & * & $* * *$ & 6 \\
\hline Friedmacher & 2014 & $* * *$ & ** & $* * *$ & 8 \\
\hline \begin{tabular}{|l|} 
Yang \\
\end{tabular} & 2014 & ** & - & $* *$ & 4 \\
\hline Madadi-Sanjani & 2015 & $* * *$ & ** & $* *$ & 7 \\
\hline Almosallam & 2016 & $* * *$ & - & $* *$ & 5 \\
\hline Diao & 2016 & ** & - & ** & 4 \\
\hline \begin{tabular}{|l|} 
Jiang \\
\end{tabular} & 2016 & ** & - & ** & 4 \\
\hline \begin{tabular}{|l|} 
Tullie \\
\end{tabular} & 2016 & $* * *$ & * & $* * *$ & 7 \\
\hline Dingemann & 2017 & *** & - & $* * *$ & 7 \\
\hline Tyson & 2017 & *** & * & $* *$ & 6 \\
\hline van den Eijnden & 2017 & $* * *$ & * & $* * *$ & 7 \\
\hline Zmora & 2016 & $* * *$ & - & ** & 5 \\
\hline \begin{tabular}{|l|} 
Michel \\
\end{tabular} & 2018 & $* * *$ & * & $* *$ & 6 \\
\hline Bing & 2019 & $* * *$ & - & $* * *$ & 6 \\
\hline de Bie & 2019 & ** & * & $* * *$ & 6 \\
\hline Dewberry & 2019 & ** & ** & $* *$ & 6 \\
\hline Gao & 2019 & ** & - & ** & 4 \\
\hline \begin{tabular}{|l|} 
Jona \\
\end{tabular} & 2001 & ** & - & $* *$ & 4 \\
\hline Mutanen & 2018 & *** & ** & $* * *$ & 8 \\
\hline \begin{tabular}{|l} 
Ramos-Gonzalez \\
\end{tabular} & 2019 & $* * *$ & * & $* * *$ & 7 \\
\hline Ren & 2018 & ** & * & $* * *$ & 6 \\
\hline Ren & 2019 & ** & * & $* * *$ & 6 \\
\hline Xiao & 2018 & ** & * & $* * *$ & 6 \\
\hline Hawkins & 2019 & *** & ** & ** & 7 \\
\hline
\end{tabular}

Table 2. Assessment of risk of bias. 


\section{Pooled proportion of Incisional Hernia (IH)}

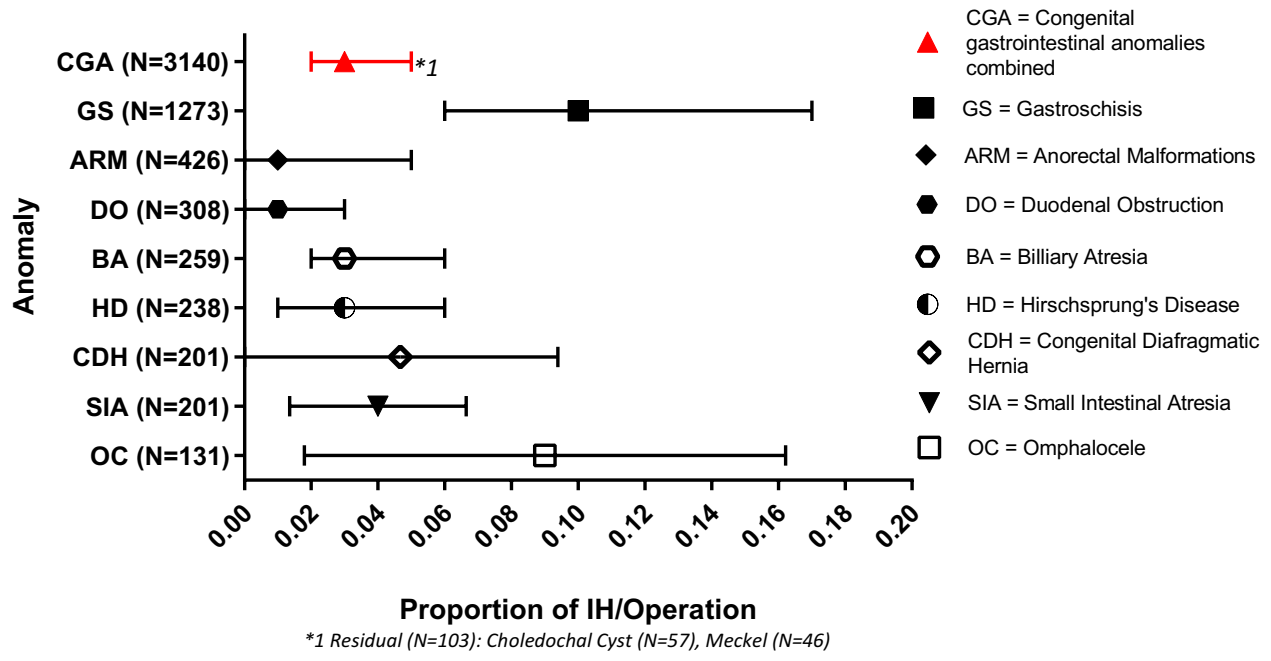

Figure 2. Pooled proportion of IH.

\begin{tabular}{|c|c|c|c|c|c|c|c|c|c|c|}
\hline Study or Subgroup & \multicolumn{2}{|c|}{ Simpel } & \multicolumn{2}{|c|}{ Complex } & Weight & \multicolumn{2}{|l|}{ Odds Ratio } & \multicolumn{2}{|c|}{$\begin{array}{c}\text { Odds Ratio } \\
\text { M-H, Random, } 95 \% \mathrm{Cl}\end{array}$} & \\
\hline Friedmacher & 1 & 94 & 2 & 14 & $44.6 \%$ & $0.06[0.01,0.77]$ & & & & \\
\hline Mutanen & 1 & 34 & 1 & 9 & $33.0 \%$ & $0.24[0.01,4.31]$ & & & & \\
\hline Zmora & 1 & 9 & 0 & 2 & $22.3 \%$ & $0.88[0.03,29.15]$ & & & & \\
\hline Total $(95 \% \mathrm{Cl})$ & & 137 & & 25 & $100.0 \%$ & $0.18[0.03,0.94]$ & & & & \\
\hline Total events & 3 & & 3 & & & & & & & \\
\hline $\begin{array}{l}\text { Heterogeneity: Tau } \\
\text { Test for overall effect }\end{array}$ & $\begin{array}{l}0.00 ; \mathrm{Ch} \\
Z=2.04\end{array}$ & $\begin{array}{l}P=1.5 \\
P=0.0\end{array}$ & 4) $d f=2($ & $=0.4$ & $7)\left._{i}\right|^{2}=0 \%$ & & $\frac{1}{0.002}$ & ${ }^{0.1}$ Simpel & $\begin{array}{r}10 \\
\text { Complex }\end{array}$ & $\frac{1}{500}$ \\
\hline
\end{tabular}

Figure 3. Forest plot simple vs complex GS.

Type of surgery. We calculated pooled proportions separately for all cases operated by laparoscopy and all cases operated by laparotomy as described in Table 1. For infants treated with by laparoscopy the pooled proportion was 0.01 (95\% CI $\left.0.01-0.03 ; \mathrm{n}=7 / 536 ; \mathrm{I}^{2}=0 \% ; p=0.00\right)^{18,22,25,26,37,39,40,42,50,51,59,62}$. For infants treated by laparotomy the pooled proportion was $0.02\left(95 \%\right.$ CI $0.01-0.04 ; n=26 / 1098 ; I^{2}=39 \%$; $p=0.76)^{15,17,21,22,28,29,32,33,37,43,45,46,49,52,53,55-57,59,63}$. Of the studies that did report on the location of the incision, transverse incision was most reported. Therefore, no subgroup analysis was done based on the location of incision.

History of stoma. All studies that reported on the history of stoma were articles describing anorectal malformations (ARM). Together, these studies contained four hernias. Two of which were not at the stoma site, but were reported as port-site hernia following laparoscopic assisted anorectoplasty ${ }^{22}$. The other two were seen at the site of stoma ${ }^{23}$. There were two articles describing ARM treatment without a stoma, no hernias occurred in these cohorts ${ }^{26,62}$.

Gastroschisis. Subgroup analysis within the GS studies showed a reduced risk of IH for simple gastroschisis compared to complex (Fig. 3); Odds ratio 0.18 (95\% CI 0.03-0.94; $p=0.04 ; \mathrm{I}^{2}=0 \%$ ).

Also, an increased risk of IH was present when SILO closure was performed compared to primary closure (Fig. 4) with an odds ratio of 3.09 (95\% CI 1.63-5.87; $\left.p \leq 0.01 ; \mathrm{I}^{2}=27 \%\right)$.

\section{Discussion}

This systematic review pooled the reported proportions on incisional hernia following abdominal surgery for congenital anomalies in infants. These proportions approximate the incidences of these complications. Therefore, our reported approximation of the incidence of IH was 3\%. Within the different congenital anomalies gastroschisis patients are most at risk with an approximated incidence of $10 \%$. In subgroup analysis complex gastroschisis (patients with GS and additional anomalies) and SILO closure were identified as risk factors for IH.

Studies reporting on laparoscopy and laparotomy seem to have similar incidences of IH although, due to the design of included studies, we were not able to compare studies. Still, this seems to be in line with previous cohort studies that focused on incisional hernia specifically in pediatric patients. These studies opted that the 


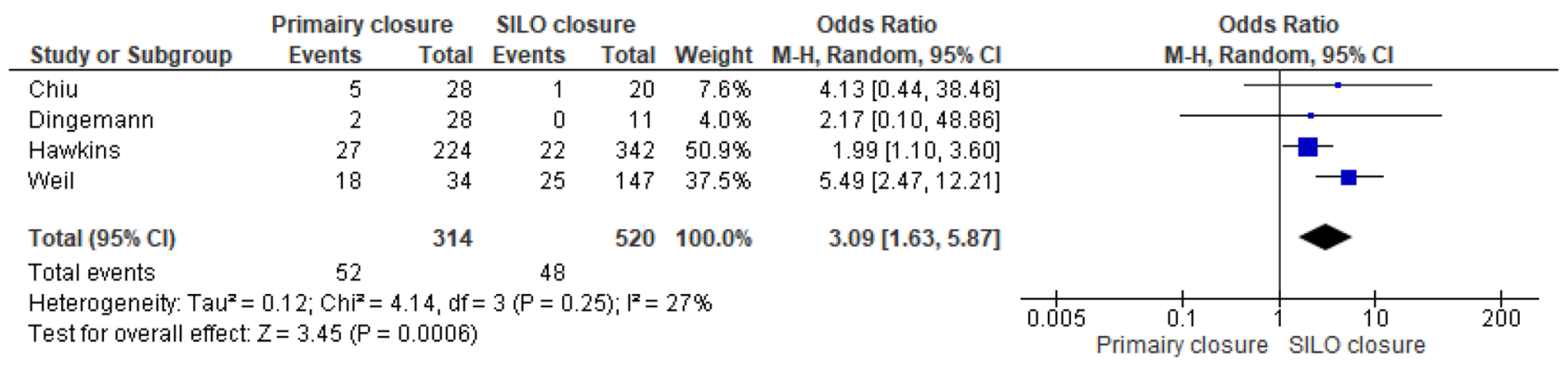

Figure 4. Forest plot SILO vs primary closure.

occurrence of IH seems to be more related to specific diagnosis instead of mode of surgery ${ }^{6,7}$. Within the included studies type of incision was only scarcely reported. Out of those that did, none reported the use of a midline incision. Transverse incision was the most reported type of incision. The use of this incision in infants provides a surgeon the best exposure to the abdominal cavity in neonates. The abdominal cavity of infants resembles a horizontal ellipsoid. With age and growth this ellipsoid changes into vertical position ${ }^{65}$. Thus, the younger the child the better visualization is obtained by using a transverse incision. Transverse incisions have been shown to have a lower incidence of $\mathrm{IH}$ compared to midline incision in adults ${ }^{66,67}$.

Previous studies suggested that the acquired newborn abdominal diseases necrotizing enterocolitis and pyloromyotomy are at higher risk for the development of $\mathrm{IH}^{7,68}$. Our review shows that the congenital abdominal wall defects gastroschisis and omphalocele should be added to this list.

Gastroschisis and omphalocele showed highest incidences of IH compared to the other congenital abdominal anomalies. Both anomalies are characterized by an abdominal wall defect with protruding viscera. In omphalocele, the viscera are covered with a membrane whilst in gastroschisis cases the viscera are not covered and thus more susceptible to infection. In order to surgically repair the defect, the viscera have to be reduced intraabdominally. The primary goal of surgical repair is to close the defect as soon as possible, as to decrease the risk of infection, whilst simultaneously minimizing the risk of ischemic injury to the viscera due to increased intra-abdominal pressure (IAP) ${ }^{69-72}$. An increase of pressure between $0-15 \mathrm{mmHg}$ is accepted because of the low risk of abdominal compartment syndrome $\mathrm{e}^{70}$. However, even this increased outwards abdominal pressure during the wound healing process increases fascial tension, which could cause the increased incidence of $\mathrm{IH}^{34}$. Since 2004 an alternative method for a select group of patients named sutureless closure was proposed by methods of primary reduction and covering of the gastroschisis defect by watertight dressing and the umbilical cord ${ }^{73}$. This technique supposedly minimizes IAP and allows for spontaneous closure ${ }^{74}$. It is reported that this technique increases the risk of umbilical hernias compared to sutured closure. Still these hernias seem to resolve, not requiring redo surgery and sutureless closure seems to overall entail less complications ${ }^{58,75,76}$. This also might be the case for sutured closure. Out of six included studies that reported on redo surgery only 17 of the 31 hernias needed reoperation. It must be noted that most studies did not report on redo surgery.

Most gastroschisis cases are isolated conditions, but in $10 \%$ associated anomalies like intestinal atresias or necrotizing enterocolitis occur resulting in complex gastroschisis ${ }^{72}$. Our results show that simple gastroschisis has an odds-ratio of 0.18 to develop an IH compared to complex gastroschisis. In general, complex cases are associated with both longer parental nutrition and length of hospital stay ${ }^{77}$. This combination of impaired nutritional status and multiple anomalies could accumulate to a multifactorial cause of increased IH incidence.

We have shown that SILO closure increases the risk of IH compared to primary closure. SILO placement is mostly considered when the viscera cannot be reduced into the abdominal cavity because of bowel oedema. This oedema might result in higher IAP leading to an increase in the chances of IH. In a study comparing primary closure with SILO closure it was shown that the incidence of IH increased with longer duration of SILO reduction ${ }^{34}$.

Since the incidence in incisional hernia in the pediatric population is low, most cohort studies only describe limited numbers of patients with an incisional hernia. Still, in most of these studies thorough statistical analysis is done, often by chi-square or regression analysis. However, both analyses demand a sufficient amount of hernia cases ensuring the least expected count to be five for chi-squared statistics and a minimum of ten hernias per one controlling variable (events per variable (EPV)) for any form of regression analysis ${ }^{78,79}$. Not abiding these statistical rules can lead to inaccurate results causing conclusions to be, to some extent, unsupported or deceptive. Future research should ensure statistical power with a sufficiently large cohort. The incidence provided by this review can aid in power size calculations.

This review was limited because none of the included studies used a specific classification for incisional hernias or described the way they were diagnosed. Moreover, many studies did not report on duration of follow-up or had a follow up of less than a year, possibly resulting in missed incisional hernias. Also, different surgical approaches and disease severities were included. These differences dissolve when combining the study results into proportional meta-analysis, which could have influenced our results. The broad inclusion criteria, resulting in differences between compared studies, can partly explain the broad confidence intervals of gastroschisis and omphalocele. In adults, consensus has been reached that an incisional hernia should be classified by its location, length and width ${ }^{80}$. Whilst infantile incisional hernias might differ from adults, it seems advisable for prospective studies to include these characteristics as well as to describe the diagnostic modality as to aid in the generalizability of the interpretations. Using any form of diagnostic imaging will increase the total amount of detected IHs. Yet, this increase will be accompanied with disagreement between observers, as is the case in adults, making 
the IHs less generalizable which is why we suggest physical examination could be sufficient ${ }^{81}$. In our opinion, the clinical significance of IHs in infants undetectable by physical examination is doubtful. Smaller hernias have been reported to close without necessitating surgery, as is also the case in congenital umbilical hernias ${ }^{7}$. Since most IHs develop within a year after surgery it is desirable to plan an extra repeat visit at least a year after surgery as part of the research protocol ${ }^{6}$.

Another limitation of our study is that most included studies did not describe the incisional hernia cases in detail. Often, just the total number was noted without describing further case characteristics. This withheld us from thoroughly analyzing indications for redo-surgery or known risk factors such as having a history of stoma or surgical site infection. However, for gastroschisis specifically, though these finding are based on nonrandomized retrospective cohort studies, our results suggest that SILO closure and complex cases are more at risk of IH. The high overall heterogeneity seems to be fairly explained by the spread in IH proportions within gastroschisis studies. This spread in its turn could be explained by differences in distribution of the described risk factors. Other anomalies showed moderate to low heterogeneity.

\section{Conclusion}

This systematic review shows that the incidence of incisional hernia is $3 \%$ all studies on surgical correction of abdominal congenital anomalies in infants are combined. Overall the incidences seem comparable between studies reporting on laparoscopies and laparotomies. Gastroschisis patients are most at risk for developing IH with an approximated incidence of $10 \%$. In subgroup analysis complex gastroschisis and SILO closure were identified as significant risk factors for $\mathrm{IH}$.

\section{Data availability}

Data available on request.

Received: 15 May 2020; Accepted: 4 November 2020

Published online: 03 December 2020

\section{References}

1. Dietz, U. A., Menzel, S., Lock, J. \& Wiegering, A. The Treatment of Incisional Hernia. Deutsch. Arzteblatt Int. 115, 31-37. https:// doi.org/10.3238/arztebl.2018.0031 (2018).

2. Nacef, K. et al. Trocar site post incisional hernia: about 19 cases. The Pan African medical journal 29, 183. https://doi.org/10.11604 /pamj.2018.29.183.14467 (2018).

3. McCann, M. E. et al. Neurodevelopmental outcome at 5 years of age after general anaesthesia or awake-regional anaesthesia in infancy (GAS): an international, multicentre, randomised, controlled equivalence trial. Lancet (Lond., Engl.) 393, 664-677. https ://doi.org/10.1016/s0140-6736(18)32485-1 (2019).

4. Sun, L. Early childhood general anaesthesia exposure and neurocognitive development. Br J Anaesth 105(Suppl 1), i61-i68. https ://doi.org/10.1093/bja/aeq302 (2010)

5. Itatsu, K. et al. Incidence of and risk factors for incisional hernia after abdominal surgery. Br. J. Surg. 101, 1439-1447. https://doi. org/10.1002/bjs.9600 (2014).

6. Mullassery, D., Pedersen, A., Robb, A. \& Smith, N. Incisional hernia in pediatric surgery-experience at a single UK tertiary centre. J. Pediatr. Surg. 51, 1791-1794. https://doi.org/10.1016/j.jpedsurg.2016.06.013 (2016).

7. Tanaka, K. et al. Risk factors for incisional hernia in children. World J. Surg. 42, 2265-2268. https://doi.org/10.1007/s00268-0174434-4 (2018).

8. Cost, N. G. et al. Hernia after pediatric urological laparoscopy. J. Urol. 183, 1163-1167. https://doi.org/10.1016/j.juro.2009.11.053 (2010).

9. Paya, K., Wurm, J., Fakhari, M., Felder-Puig, R. \& Puig, S. Trocar-site hernia as a typical postoperative complication of minimally invasive surgery among preschool children. Surg. Endosc. 22, 2724-2727. https://doi.org/10.1007/s00464-008-9768-4 (2008).

10. Taguchi, T., Nagata, K., Kinoshita, Y. \& Esumi, G. Progress in and outcomes of neonatal surgery over the past 50 years. Nihon Geka Gakkai zasshi 115, 306-311 (2014).

11. Tzong, K. Y., Han, S., Roh, A. \& Ing, C. Epidemiology of pediatric surgical admissions in US children: data from the HCUP kids inpatient database. J. Neurosurg. Anesthesiol. 24, 391-395. https://doi.org/10.1097/ANA.0b013e31826a0345 (2012).

12. Shamseer, L. P. et al. Preferred reporting items for systematic review and meta-analysis protocols (PRISMA-P) 2015: elaboration and explanation. BMJ (Clin. Res. Ed.) 350(g7647), 2015. https://doi.org/10.1136/bmj.g7647 (2015).

13. Wells, G. A. et al. Checklists of methodological issues for review authors to consider when including non-randomized studies in systematic reviews. Res. Synth. Methods 4, 63-77. https://doi.org/10.1002/jrsm.1077 (2013).

14. Higgins, J. P. T., Thompson, S. G., Deeks, J. J. \& Altman, D. G. Measuring inconsistency in meta-analyses. . BMJ (Clin. Res. Ed.) 327, 557-560. https://doi.org/10.1136/bmj.327.7414.557 (2003).

15. Almosallam, O. I., Aseeri, A. \& Shanafey, S. A. Outcome of loop versus divided colostomy in the management of anorectal malformations. Ann. Saudi Med. 36, 352-355 (2016).

16. Banieghbal, B. \& Beale, P. G. Minimal access approach to jejunal atresia. J. Pediatr. Surg. 42, 1362-1364 (2007).

17. Bianchi, A. One-stage neonatal reconstruction without stoma for Hirschsprung's disease. Semin. Pediatr. Surg. 7, 170-173 (1998).

18. Bing, L. et al. Modifications to expose porta hepatis for laparoscopic portoenterostomy easier in Biliary Atresia. J. Surg. Res. 233, 368-375 (2019).

19. Chiu, B. et al. Closing arguments for gastroschisis: Management with silo reduction. J. Perinat. Med. 34, 243-245 (2006).

20. Dariel, A., Poocharoen, W., De Silva, N., Pleasants, H. \& Gerstle, J. T. Secondary plastic closure of gastroschisis is associated with a lower incidence of mechanical ventilation. Eur. J. Pediatr. Surg. 25, 34-40 (2015).

21. De Bie, F. et al. Early surgical complications after congenital diaphragmatic hernia repair by thoracotomy vs. laparotomy: a bicentric comparison. J. Pediatr. Surg. 55, 2105-2110 (2020).

22. De Vos, C., Arnold, M., Sidler, D. \& Moore, S. W. A comparison of laparoscopic-assisted (LAARP) and posterior sagittal (PSARP) anorectoplasty in the outcome of intermediate and high anorectal malformations. S. Afr. J. Surg. 49, 39-43 (2011).

23. Demirogullari, B. et al. Ostomy complicatIons in patients with anorectal malformations. Pediatr. Surg. Int. 27, 1075-1078 (2011).

24. Dewberry, L., Hilton, S., Gien, J., Liechty, K. W. \& Marwan, A. I. Flap repair in congenital diaphragmatic hernia leads to lower rates of recurrence. J. Pediatr. Surg. 54, 2487-2491 (2019).

25. Diao, M., Li, L., Li, Q., Ye, M. \& Cheng, W. Challenges and strategies for single-incision laparoscopic Roux-en-Y hepaticojejunostomy in managing giant choledochal cysts. Int. J. Surg. (Lond. Engl.) 12, 412-417 (2014). 
26. Diao, M. et al. Congenital anomaly rectified at birth: one-stage single-incision laparoscopic-assisted anorectoplasty for newborns with anorectal malformations and recto-urethral fistula. Surg. Endosc. 30, 5156-5164 (2016).

27. Dingemann, C. et al. Surgical management of congenital abdominal wall defects in Germany: a population-based study and comparison with literature reports. Eur. J. Pediatr. Surg. 27, 516-525 (2017).

28. Escobar, M. A. et al. Long-term outcomes in total colonic aganglionosis: a 32-year experience. J. Pediatr. Surg. 40, 955-961 (2005).

29. Escobar, M. A. et al. Duodenal atresia and stenosis: Long-term follow-up over 30 years. J. Pediatr. Surg. 39, 867-871 (2004).

30. Festen, S. et al. Excellent long-term outcome for survivors of apple peel atresia. J. Pediatr. Surg. 37, 61-65 (2002).

31. Friedmacher, F., Hock, A., Castellani, C., Avian, A. \& Höllwarth, M. E. Gastroschisis-related complications requiring further surgical interventions. Pediatr. Surg. Int. 30, 615-620 (2014).

32. Gao, R. et al. Enhanced recovery after surgery in pediatric gastrointestinal surgery. J. Int. Med. Res. 47, 4815-4826 (2019).

33. Ghaffarpour, N., Svensson, P. J., Svenningsson, A., Wester, T. \& Mesas Burgos, C. Supraumbilical incision with U-u umbilicoplasty for congenital duodenal atresia: the Stockholm experience. J. Pediatr. Surg. 48, 1981-1985 (2013).

34. Hawkins, R. B. et al. Immediate versus silo closure for gastroschisis: results of a large multicenter study. J. Pediatr. Surg. https:// doi.org/10.1016/j.jpedsurg.2019.08.002 (2019).

35. Henrich, K., Huemmer, H. P., Reingruber, B. \& Weber, P. G. Gastroschisis and omphalocele: treatments and long-term outcomes. Pediatr. Surg. Int. 24, 167-173 (2008).

36. Ibrahim, M. M. Two Trocar laparoscopic repair of morgagni hernia in infant and childhood: simplified technique. World J. Laparosc. Surg. 6, 47-51 (2013).

37. Jensen, A. R. et al. Laparoscopic versus open treatment of congenital duodenal obstruction: multicenter short-term outcomes analysis. J. Laparoendosc. Adv. Surg. Tech. 23, 876-880 (2013).

38. Jiang, W. et al. Use of small intestinal submucosal and acellular dermal matrix grafts in giant omphaloceles in neonates and a rabbit abdominal wall defect model. J. Pediatr. Surg. 51, 368-373 (2016).

39. Jona, J. Z. Personal experience with 50 laparoscopic procedures for Hirschsprung's disease in infants and children. Pediatr. Endosurg. Innov. Tech. 5, 361-363 (2001).

40. Kozlov, Y. et al. Keyhole approach for repair of congenital duodenal obstruction. Eur. J. Pediatr. Surg. 21, 124-127 (2011).

41. Lee, S. L. et al. Initial nonoperative management and delayed closure for treatment of giant omphaloceles. J. Pediatr. Surg. 41, 1846-1849 (2006).

42. Li, B., Chen, W. B., Wang, S. Q., Liu, S. L. \& Li, L. Laparoscopy-assisted surgery for neonatal intestinal atresia and stenosis: a report of 35 cases. Pediatr. Surg. Int. 28, 1225-1228 (2012).

43. Madadi-Sanjani, O., Carl, N., Longerich, T., Petersen, C. \& Andruszkow, J. H. K. Inguinal hernias represent the most frequent surgical complication after kasai in biliary atresia infants. BioMed Res. Int. 2015, 383791 (2015).

44. Michel, J. L. et al. ZORRO: Z omphaloplasty repair for omphalocele. J. Pediatr. Surg. 53, 1424-1427 (2018).

45. Mutanen, A., Koivusalo, A. \& Pakarinen, M. Complicated gastroschisis is associated with greater intestinal morbidity than gastroschisis or intestinal atresia alone. Eur. J. Pediatr. Surg. 28, 495-501 (2018).

46. Onen, A., Cigdem, M. K., Ozturk, H., Otcu, S. \& Dokucu, A. I. When to resect and when not to resect an asymptomatic Meckel's diverticulum: an ongoing challenge. Pediatr. Surg. Int. 19, 57-61 (2003).

47. Orion, K. C. et al. Outcomes of plastic closure in gastroschisis. Surgery 150, 177-185 (2011).

48. Payne, N. R. et al. A cross-sectional, case-control follow-up of infants with gastroschisis. J. Neonat.-Perinat. Med. 3, 207-215 (2010).

49. Ramos-Gonzalez, G. et al. Predictors of need for liver transplantation in children undergoing hepatoportoenterostomy for biliary atresia. J. Pediatr. Surg. 54, 1127-1131 (2019).

50. Ren, X. et al. Single-incision laparoscopic-assisted anorectoplasty versus three-port laparoscopy in treatment of persistent cloaca: a midterm follow-up. J. Laparoendosc. Adv. Surg. Tech. Part A 28, 1540-1547 (2018).

51. Ren, X. et al. Single-incision laparoscopic-assisted anorectoplasty for treating children with intermediate-type anorectal malformations and rectobulbar fistula: a comparative study. Pediatr. Surg. Int. 35, 1255-1263 (2019).

52. Santos, M. C., Giacomantonio, J. M. \& Lau, H. Y. Primary Swenson pull-through compared with multiple-stage pull-through in the neonate. J. Pediatr. Surg. 34, 1079-1081 (1999).

53. Sauer, C. J., Langer, J. C. \& Wales, P. W. The versatility of the umbilical incision in the management of Hirschsprung's disease. J. Pediatr. Surg. 40, 385-389 (2005).

54. Saxena, A. \& Willital, G. H. Omphalocele: clinical review and surgical experience using dura patch grafts. Hernia J. Hernias Abdom. Wall Surg. 6, 73-78 (2002).

55. Stollman, T. H. et al. Decreased mortality but increased morbidity in neonates with jejunoileal atresia; a study of 114 cases over a 34-year period. J. Pediatr. Surg. 44, 217-221 (2009).

56. Takahashi, Y. et al. Umbilical crease incision for duodenal atresia achieves excellent cosmetic results. Pediatr. Surg. Int. 26, 963-966 (2010).

57. Teitelbaum, D. H. \& Coran, A. G. Primary pull-through in the newborn. Semin. Pediatr. Surg. 7, 103-107 (1998).

58. Tullie, L. G. C. et al. Umbilical hernia following gastroschisis closure: A common event?. Pediatr. Surg. Int. 32, 811-814 (2016).

59. Tyson, A. F., Sola, R. Jr., Arnold, M. R., Cosper, G. H. \& Schulman, A. M. Thoracoscopic versus open congenital diaphragmatic hernia repair: single tertiary center review. J. Laparoendosc. Adv. Surg. Tech. Part A 27, 1209-1216 (2017).

60. van den Eijnden, M. H. A. et al. Choledochal malformation in children: lessons learned from a dutch national study. World J. Surg. 41, 2631-2637 (2017).

61. Weil, B. R., Leys, C. M. \& Rescorla, F. J. The jury is still out: changes in gastroschisis management over the last decade are associated with both benefits and shortcomings. J. Pediatr. Surg. 47, 119-124 (2012).

62. Xiao, H. et al. One-stage laparoscopic-assisted anorectoplasty for neonates with anorectal malformation and recto-prostatic or recto-bulbar fistula according to the krickenbeck classification. J. Laparoendosc. Adv. Surg. Tech. Part A 28, 1029-1034 (2018).

63. Yang, L. et al. Two-stage laparoscopic approaches for high anorectal malformation: transumbilical colostomy and anorectoplasty. J. Pediatr. Surg. 49, 1631-1634 (2014).

64. Zmora, O., Castle, S. L., Papillon, S. \& Stein, J. E. The biological prosthesis is a viable option for abdominal wall reconstruction in pediatric high risk defects. Am. J. Surg. 214, 479-482 (2017).

65. Gauderer, M. W. A rationale for routine use of transverse abdominal incisions in infants and children. J. Pediatr. Surg. 16, 583-586. https://doi.org/10.1016/0022-3468(81)90009-9 (1981).

66. Lee, L. et al. Incisional hernia after midline versus transverse specimen extraction incision: a randomized trial in patients undergoing laparoscopic colectomy. Ann. Surg. 268, 41-47. https://doi.org/10.1097/sla.0000000000002615 (2018).

67. Halm, J. A., Lip, H., Schmitz, P. I. \& Jeekel, J. Incisional hernia after upper abdominal surgery: a randomised controlled trial of midline versus transverse incision. Hernia J. Hernias Abdom. Wall Surg. 13, 275-280. https://doi.org/10.1007/s10029-008-0469-7 (2009).

68. Mullassery, D., Pedersen, A., Robb, A. \& Smith, N. Incisional hernia in pediatric surgery-experience at a single UK tertiary centre. J. Pediatr. Surg. 51, 1791-1794. https://doi.org/10.1016/j.jpedsurg.2016.06.013 (2016).

69. Christison-Lagay, E. R., Kelleher, C. M. \& Langer, J. C. Neonatal abdominal wall defects. Semin. Fetal Neonat. Med. 16, 164-172. https://doi.org/10.1016/j.siny.2011.02.003 (2011).

70. Gamba, P. \& Midrio, P. Abdominal wall defects: prenatal diagnosis, newborn management, and long-term outcomes. Semin. Pediatr. Surg. 23, 283-290. https://doi.org/10.1053/j.sempedsurg.2014.09.009 (2014). 
71. Islam, S. Advances in surgery for abdominal wall defects: gastroschisis and omphalocele. Clin. Perinatol. 39, 375-386. https://doi. org/10.1016/j.clp.2012.04.008 (2012).

72. Ledbetter, D. J. Congenital abdominal wall defects and reconstruction in pediatric surgery: gastroschisis and omphalocele. Surg. Clin. N. Am. 92, 713-727. https://doi.org/10.1016/j.suc.2012.03.010 (2012).

73. Sandler, A., Lawrence, J., Meehan, J., Phearman, L. \& Soper, R. A “plastic” sutureless abdominal wall closure in gastroschisis. J. Pediatr. Surg. 39, 738-741. https://doi.org/10.1016/j.jpedsurg.2004.01.040 (2004).

74. Petrosyan, M. \& Sandler, A. D. Closure methods in gastroschisis. Semin. Pediatr. Surg. 27, 304-308. https://doi.org/10.1053/j.sempe dsurg.2018.08.009 (2018).

75. Youssef, F., Gorgy, A., Arbash, G., Puligandla, P. S. \& Baird, R. J. Flap versus fascial closure for gastroschisis: a systematic review and meta-analysis. J. Pediatr. Surg. 51, 718-725. https://doi.org/10.1016/j.jpedsurg.2016.02.010 (2016).

76. Miyake, H., Seo, S., O'Connell, J. S., Janssen Lok, M. \& Pierro, A. Safety and usefulness of plastic closure in infants with gastroschisis: a systematic review and meta-analysis. Pediatr. Surg. int. 35, 107-116. https://doi.org/10.1007/s00383-018-4381-7 (2019).

77. Melov, S. J. et al. Complexity of gastroschisis predicts outcome: epidemiology and experience in an Australian tertiary centre. BMC Pregnancy Childbirth 18, 222-222. https://doi.org/10.1186/s12884-018-1867-1 (2018).

78. Austin, P. C. \& Steyerberg, E. W. The number of subjects per variable required in linear regression analyses. J. Clin. Epidemiol. 68, 627-636. https://doi.org/10.1016/j.jclinepi.2014.12.014 (2015).

79. McHugh, M. L. The chi-square test of independence. Biochem. Med. (Zagreb.) 23, 143-149. https://doi.org/10.11613/bm.2013.018 (2013).

80. Muysoms, F. E. et al. Classification of primary and incisional abdominal wall hernias. Hernia 13, 407-414. https://doi.org/10.1007/ s10029-009-0518-x (2009).

81. Kroese, L. F., Sneiders, D., Kleinrensink, G. J., Muysoms, F. \& Lange, J. F. Comparing different modalities for the diagnosis of incisional hernia: a systematic review. Hernia 22, 229-242. https://doi.org/10.1007/s10029-017-1725-5 (2018).

\section{Author contributions}

L.E.S. and R.V. developed the search strategy. All authors contributed to the development of the selection criteria. L.E.S. and D.N. were first and second reviewer. J.D., G.M., E.vH. and W.dJ. provided clinical expertise. L.E.S., J.D. and G.M. provided statistical and research conducting expertise. LES drafted the manuscript. All authors read, provided feedback and approved the final manuscript.

\section{Competing interests}

The authors declare no competing interests.

\section{Additional information}

Supplementary information is available for this paper at https://doi.org/10.1038/s41598-020-77976-1.

Correspondence and requests for materials should be addressed to L.D.E.S.

Reprints and permissions information is available at www.nature.com/reprints.

Publisher's note Springer Nature remains neutral with regard to jurisdictional claims in published maps and institutional affiliations.

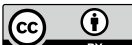

Open Access This article is licensed under a Creative Commons Attribution 4.0 International License, which permits use, sharing, adaptation, distribution and reproduction in any medium or format, as long as you give appropriate credit to the original author(s) and the source, provide a link to the Creative Commons licence, and indicate if changes were made. The images or other third party material in this article are included in the article's Creative Commons licence, unless indicated otherwise in a credit line to the material. If material is not included in the article's Creative Commons licence and your intended use is not permitted by statutory regulation or exceeds the permitted use, you will need to obtain permission directly from the copyright holder. To view a copy of this licence, visit http://creativecommons.org/licenses/by/4.0/.

(C) The Author(s) 2020 